\title{
Family planning program under low fertility: where to go
}

\author{
Baochang $\mathrm{Gu}^{1}$ (1)
}

Received: 4 March 2021 / Accepted: 11 March 2021 / Published online: 18 March 2021

(c) The Author(s) 2021

\begin{abstract}
This commentary is intended to take China as a case to discuss the mission of the family planning program under low fertility scenario. After a brief review of the initiation of family planning program in the 1970s, as well as the reorientation of family planning program since ICPD in 1994, it will focus on the new mission for the family planning program under low fertility scenario in the twenty-first century, in particular concerning the issue of induced abortion among the others. Given the enormous evidence of unmet needs in reproductive health as identified in the discussion, it is argued that family planning programmes are in fact even more needed than ever before under low-fertility scenario, and should not be abandoned but strengthened, which clearly has nothing to do to call back to the program for population control in the 1970s-1980s, and nor even go back to the program for "two reorientations" in the 1990s, but to aim to serving the people to fulfill their reproductive health and reproductive rights in light of ICPD and SDGs, and to become truly integral component of "Healthy China 2030" Strategy.
\end{abstract}

Keywords Family planning program $\cdot$ Low fertility $\cdot$ China $\cdot$ Abortion · Unmet needs

\section{Initiation of the family planning program}

This commentary is intended to take China as a case to discuss the mission of the family planning program under low fertility scenario. It will begin with a brief review of the initiation of family planning program in the 1970s in China (the 1960s more broadly in the world), followed by reorientation of family planning program since ICPD in 1994, as well as the new mission for the family planning program under low fertility scenario in the twenty-first century.

While as emerged from the struggle by the elite feminists in the Western countries in the early twentieth century as well as from the demands among the working

Baochang Gu

baochanggu@gmail.com

1 Center for Population and Development Policy Studies, Fudan University, Shanghai, China 
women in urban China in the early 1950s, primarily for the emancipation of women from heavy burden of childbearing, family planning program (FPP) was not until the 1960s (or the 1970s in the case of China) to turn itself into a societal movement (or worldwide movement) and even steadily escalated up to the top priority of national agenda in many countries, such as in the cases of India and China, with primary concern of curbing rapid population growth (Sinding, 2007). The complex and uneasy initiations of the family planning programs "in difficult settings that had little prior experience to draw upon", as "a new fertility determinant-organized actions by whole societies to bring birthrates down to match falling death rates" in many countries over the world, have been vividly documented in the World Bank publication The Global Family Planning Revolution: Three Decades of Population Policies and Programs, and claimed to be "first time in human history, of organized national programs devoted the challenge of excessive and unwanted fertility" (Robinson \& Ross, 2007).

As in China due largely to the control of infectious disease and improvement of hygiene conditions, mortality notably infant mortality, was first cut in half in the 1950s, with fertility remaining at the level around 5 to 6 children per woman during the period, which resulted in the acceleration of population growth in the 1960s. As a response to the rapid population growth of close to 3 percent per annum, the Chinese government launched a nationwide family planning program in the early 1970s. The programme incorporated a strategy of "wan" (late marriage and late childbearing), " $x i "$ (longer birth spacing) and "shao" (fewer children in life), along with the free provision of modern contraceptives to all citizens. The decade of the 1970s witnessed a dramatic decline in China's fertility, from 5.79 in 1970 to 2.75 in 1979, a reduction of more than half in a period of less than a decade. Most of the reduction in fertility was due to presumably the aversion of the unwanted childbearing at high parities, particularly in urban areas.

Encouraged by the achievements of the fertility reduction in the 1970s while facing an economy at the edge of collapse, the government decided to tighten its fertility policy in the early 1980s to call for one child per couple (Gu et al., 2007), along with set-up of extensive contraceptive supply network all over the country. Though China's total fertility rate (TFR) was fluctuated around 2.5 children per woman during the 1980s, an analysis of parity progression ratios revealed that reductions occurred particularly among the high parities both in urban and rural areas as well as in remote regions. By the early 1990s, China's fertility had further fallen to the level below the replacement.

Recent several Chinese censuses have repeatedly reported a very low TFR one after another, from 1.22 in 2000, 1.18 in 2010, and 1.05 in 2015, which triggered endless debates and questioning on quality of data. To take into account the possible statistical errors and underreporting, the adjusted level still shows a downward trend of fertility in China (Gu \& Hou, 2018). Evidence also suggests the weakening childbearing desire particularly among the younger generations (Basten \& Gu, 2013; Hou et al., 2014). Given the situation, the government announced the partial relaxation to allow the couples with one spouse as a single child to have second child in November 2013, and further allowed all the couples to have two children in October 2015, 
which declared the official termination of the 35 years long one-child per couple dominated policy in China.

\section{Reorientation of the family planning program}

The Program of Action (PoA) adopted at the International Conference on Population and Development (ICPD) in Cairo in 1994 argues for addressing population issues from a broader concept of reproductive health and reproductive rights. It urges a client-centered, service-oriented, user-friendly, right-based and gender-sensitive approach to family planning programs. The ICPD serves as a milestone redefining linkages between population and sustainable development. Immediate after the ICPD, the Chinese government issued an official call for "Two Reorientations" of the family planning program in both guiding ideology and implementation approach, from an emphasis on demographic targets towards client-centered approaches, and from a narrow focus on contraceptive prevalence towards relevant integration with objectives on reproductive health and women's empowerment.

As a concrete measure in implementation of PoA/ICPD in China and the two reorientations in FPP, an experiment was initiated to introduce the quality of care approach into China's family planning program as demonstration of the feasibility of the innovation along the principles of ICPD. In the experiment areas, the concept of quality of care became gradually but widely accepted by the program managers and service providers. The six elements of quality of care were posted in many FP clinics as guidance for service provision. Birth quotas and targets were totally abandoned, the birth permit used to be required prior to pregnancy was removed, couples were able to decide on their own will the timing for childbearing. The parity-specific policy on contraceptive use was discontinued, instead introduced the informed choice of contraceptive methods.

Local people who were involved in the pilot-including family planning programme managers, service providers, clients and government leaders-were convinced that quality of care was the best approach to implement the programme. The results of the pilot project were tangible, convincing, and apparently sustainable. The pilot demonstrated the feasibility of a service-oriented approach to the programme in the context of China. With this new approach, not only did the programme become more widely accepted, leading to greater impact and better demographic outcomes, but more importantly it provided better services to clients and protected their health and rights.

China's QoC initiative was later selected as one of the 10 cases of Innovative Experiences in the PPD/UNFPA/UNDP publication (Partners in Population and Development [PPD], 2011). It was stated that "China case study is in many ways an illustration of the basic need to strengthen the quality of care in family planning services, as called for in the Programme of Action of the ICPD." And it "demonstrates that, by reorienting the focus, upgrading services and improving facilities, the country succeeded not only in attaining low and stable fertility levels but also in generating among the people an improved awareness of reproductive rights and benefits, an 
improved relationship between clients and service providers, and an improved image of the family planning programme" (PPD, 2011: 15-16).

Many people involved in the pilot have deeply regarded it as the most significant experience of their personal careers associated with family planning programmes. A collection of their personal stories has been recently assembled and published, with the title Efforts in Memory: Quality of Care Initiative in China's Family Planning Programme (Xie et al., 2020).

\section{New mission of the family planning program}

Nevertheless as stated above, for a long time in China as well as in many developing countries, the driving force behind family planning programmes has been primarily demographic concerns, and such programmes were viewed as a means to reduce fertility, so as to slow down population growth, and facilitate economic development (Robinson \& Ross, 2007).

\subsection{Unmet needs}

With fertility at the level far below the replacement for so long (Guo et al., 2019), and the end of one-child policy (Wang et al., 2016), the questions arises as: should the family planning program then be terminated? If not, what is the mission for family planning program under low fertility? For many it has been identifying the family planning program as equivalent to birth restriction or even one-child policy, thus see the family planning program no longer needed. For others, it is regarded as an opportunity for a more comprehensive implementation of the family planning program in terms of reproductive health and reproductive rights as stipulated in the PoA/ICPD as well as SDGs, and to make the program more truly and fully clientcentered, service-oriented, user-friendly, right-based and gender-sensitive, as well as an important and integral part of "Healthy China 2030" Strategy.

It is evident that while the fertility has fallen to below replacement and will likely continue to go downward, the reproductive health issues do not at the same time diminish but are somehow intensified and diversified, and deserve great attention.

Under low fertility scenario young people's puberty tends to arrive earlier and marriage tends to be deferred which results in a longer period of exposure to the risk of unprepared sex and unintended pregnancy, likely to end as induced abortion.

As family planning services have traditionally been targeted at ever-married couples of childbearing age, youth and unmarried persons often have limited access to sexual and reproductive health services. The younger cohorts tend to have a higher incidence of premarital pregnancy, especially among rural migrants and those with lower educational attainment. Adolescent and unmarried persons still have unmet sexual and reproductive health needs ( $\mathrm{Li} \&$ Tian, 2017). How to prevent and reduce the induced abortion among the unmarried, as well as the subsequently infertility after marriage becomes a huge challenge to be addressed in reproductive health. 
Also, it is hard for women in remote and poor areas to access to basic maternal healthcare, and public health services tend to be less accessible to migrants, especially women, and adolescents who are more likely to have high unmet reproductive-health needs.

Low fertility also naturally suggests that the childbearing period becomes shortened and meanwhile the contraceptive period becomes longer over one's childbearing age period. Thanks to the development of contraceptive science, there are a variety of modern contraceptive methods available for informed choice to meet the diversified needs of the clients. Though as understood well, no any single method will fit to all the women and nor one method fits in all the stages of one's life. To have effective contraception over the prolong period after the completion of childbearing, it obviously requires intensified and constant professional consultation and services.

While the contraceptive prevalence rate among married women of childbearing age in China remains high, up to 83 percent since 2011, the contraceptive mix has changed significantly since the relaxation of fertility policy. For example, the IUD use has declined slightly, and sterilization has showed a dramatic decrease, at the same time the use of condoms has increased remarkably (China Family Planning Association [CFPA] and China Population \& Development Research Center [CPDRC], 2020). In particular, condom use has increased significantly since late 2015 , when the universal two-child policy was put in place. With the reduced uptake of long-term contraceptive methods and increased uptake of short-acting methods, the risk of induced abortion due to contraceptive failure tends to increase significantly (Zou et al., 2018).

With increase of life expectancy, women tend to live much longer beyond menopause. The sexual and reproductive health issues for the elderly population have long been ignored and should also be recognized and properly addressed. One acute reproductive-health issue in this regard is the removal of IUDs for large number of women at the age of menopause. For long time IUD is one of the most frequently used contraceptives in China among childbearing women, particularly in rural areas. While approaching to menopause stage it is estimated that about 6.7 million IUDs are required to be taken off, which will mount to 26 million in the next ten years (Sun et al., 2014).

\subsection{Induced abortion}

One issue to be particularly underlined in the discussion relevant to the family planning program under low fertility scenario is induced abortion. Abortion remains an issue to be better addressed with updated attention. It is well known that frequent resort to abortions can be harmful to women both physiologically and psychologically, and should be prevented and reduced by all means.

Over the most time after the early 1990s, abortion in China has been kept less than 8 million, which presumably has a lot to do with the reform in the family planning program in the spirit of ICPD concerning reproductive health and reproductive rights, as well as the "two reorientations" regarding the guiding ideology and 
implementation approach of the program, by which quality of care in service provision and informed choice of contraceptive methods have been adopted gradually in the program all over the country (Gu et al., 2019).

With the relaxation of fertility policy in 2013 the needs for prevention of births violating fertility policy and sex-selection for son preference have been gradually vanishing, the total number of abortions however was rather increased by almost one-third from 7 million during 2010-2013 to nearly 10 million during 2014-2018, according to the official statistics, which is almost at the highest level since the early 1990s, except for 2008 (CFPA and CPDRC 2020). The official statistics also show that the abortion ratio in 2018 went up to 63.9, which is even higher than that in 1991 (62.2), and the highest since 1971 except for 1983 (69.6). The abortion rate in 2018 went up to $28.33 \%$ o, from what was kept around $20 \%$ o for almost about two decades until getting it up in recent years, and at the highest since 1994 (29.1\%o).

One may ask why has the abortion rate been increasing even with the shrinking of size of childbearing women as the results of long time fertility reduction, and also why has the abortion ratio been increasing even with the decreasing of number of births due to weakening of childbearing desire particularly among the younger generations?

One explanation for the reported increase in abortions is that it might be affected by the merging of the two statistical systems of MCH and FPP with reform in government agencies in 2013. A more plausible explanatory factor is the consequences of the higher levels of unprotected sexual activity among unmarried youth as they are more likely at the risk of unintended pregnancy, as well as the frequent incidence of contraceptive failure as more married women shifted to short-term methods during the prolong period after the completion of childbearing.

Research and field survey have revealed that the incidence of abortion among unmarried adolescents not only have been increasing, in some cases even surpass that among the married, but also tend to occur among girls at younger ages and even repeatedly. Some abortions were even unfortunately not taken until the later trimester of pregnancy. Besides, the accidental pregnancies due to contraceptive failure have occurred in enormous amount among married women after their completion of childbearing (CFPA \& CPDRC, 2020).

Meantime, recent years also witness that along with the merging of Family Planning Commission with the Ministry of Health among the government agencies as well as the merging of family planning services into the $\mathrm{MCH}$ institutions at the grassroots level, many family planning clinics disappeared, many experienced family planning service providers flowed away, family planning service network is no longer functioning, family planning services and contraceptive supplies have been tremendously diminished or weakened.

It can be certainly argued with no exaggeration that the near 10 million abortions every year in China implies numerous unintended/unplanned pregnancies, which suggests huge amount of unmet needs of contraceptive supply and services, and the enormous gap to fulfill in terms of the reproductive health and rights of people at childbearing age. It certainly indicates the weakening or even absence of family planning services at all. In this regard, a high level of unmet needs for family planning among these sub-population groups is particularly implicated. What is urgent is 
to abolish the long time misconcept of "abortion is harmless", take prevention and reduction of abortion as the top priority in the assessment of reproductive health, and greatly enhance the access to the family planning services and effective birth control methods particularly for the sub-populations who are more likely exposed to the risk of unintended pregnancies, as well as the subsequent abortions.

\subsection{Services strengthening}

The above discussion should also have made it clear that the new mission of family planning program under low fertility scenario has nothing to do to call back to the program for population control in the 1970s-1980s, and nor even go back to the program for "two reorientations" in the 1990s, but to aim to serving the people to fulfill their reproductive health and reproductive rights as specified in the program of action of ICPD and the goals of SDGs, and to make itself truly integral component of "Healthy China 2030" Strategy.

The assertion that because of weakening of childbearing desire and relaxation of fertility policy, family planning services are no longer needed or insignificant, is certainly groundless. Research has on the contrary suggested that "as fertility transition progresses, the exercise of fertility control and the risk of unintended fertility both increase," and very likely "the proportion of pregnancies unplanned is highest in societies with the lowest desired family size" (Bongaarts \& Casterline, 2018). All in all, it is arguable that given the enormous evidence of unmet needs in reproductive health as identified in the discussion, family planning programmes are in fact even more needed than ever before under the low-fertility scenario, and should not be abandoned but rather strengthened to provide quality services to meet the diversified needs of people in reproductive health and family planning.

\section{Declarations}

Conflicts of interest No conflict of interests is confirmed.

Open Access This article is licensed under a Creative Commons Attribution 4.0 International License, which permits use, sharing, adaptation, distribution and reproduction in any medium or format, as long as you give appropriate credit to the original author(s) and the source, provide a link to the Creative Commons licence, and indicate if changes were made. The images or other third party material in this article are included in the article's Creative Commons licence, unless indicated otherwise in a credit line to the material. If material is not included in the article's Creative Commons licence and your intended use is not permitted by statutory regulation or exceeds the permitted use, you will need to obtain permission directly from the copyright holder. To view a copy of this licence, visit http://creativecommons.org/licen ses/by/4.0/.

\section{References}

Basten, S. \& B. Gu. (2013). Childbearing preferences, reform of family planning restrictions and the Low Fertility Trap in China. Oxford Center for Population Research Working Paper, No. 61. 
Bongaarts, J., \& Casterline, J. B. (2018). From fertility preferences to reproductive outcomes in the developing world. Population and Development Review, 44(4), 793-809.

China Family Planning Association (CFPA) and China Population and Development Research Center (CPDRC). (2020). Report on Reproductive Health in China. Beijing: Intellectual Property Publishing House. (in Chinese).

Gu, B., Wang, F., Guo, Z., \& Zhang, E. (2007). China's local and national fertility policies at the end of the twentieth century. Population and Development Review, 33(1), 129-147.

Gu, B., J. Hou. (2018). "Why is China's TFR so low? A decomposition analysis." Presented at Wittgenstein Center Conference $20183^{\text {rd }}$ Fertility Data Base Symposium, Fertility Across time and Space: Data and Research Advance, Vienna University of Economics and Business, Austria, December 5-7.

Gu, B., Z. Mao, and M. Hu. (2019). An Ongoing Journey - Review of ICPD +25 in China. China Population and Development Research Center (CPDRC) and United Nations Population Fund (UNFPA).

Guo, Z., Gietel-Basten, S., \& Gu, B. (2019). The lowest fertility rates in the world? Evidence from the 2015 Chinese $1 \%$ sample census. China Population and Development Studies, 2, 245-258.

Hou, J., Huang, S., Xin, Z., Sun, L., Zhang, H., \& Dou, D. (2014). Changes in the Chinese population's fertility intentions: 1980-2011. Social Sciences in China, 35(4), 78-97.

Li, D., \& Tian, S. (2017). Patterns and determinates of premarital pregnancy in China. Renkou Yanjiu (Population Research), 41(3), 87-100. (in Chinese).

Partners in Population and Development (PPD). (2011). Sharing Innovative Experiences, Volume 19: Experiences in Addressing Population and Reproductive Health Challenges. Global South-South Development Academy.

Robinson, W. C., \& Ross, J. A. (Eds.). (2007). The global family planning revolution: Three decades of population policies and programs. The World Bank.

Sinding, S. (2007). Overview and perspective. In W. C. Robinson \& J. A. Ross (Eds.), The global family planning revolution: Three decades of population policies and programs. The World Bank.

Sun, X., Shu, X., Zong, Z., Mao, J., Sun, Y., \& Hearst, N. (2014). Unmet sexual and reproductive health needs of women aged 50 to 64 years in rural China. Menopause: The Journal of the North Menopause Society., 22(5), 505-511.

Xie, Z., Gu, B., Zheng, Z., Liu, H., \& Ru, X. (Eds.). (2020). Efforts in memory: Quality of care initiative in China's family planning programme. Beijing: Social Sciences Academic Press. (in Chinese).

Wang, F., Gu, B., \& Cai, Y. (2016). The end of China's one-child policy. Studies in Family Planning, 47(1), 83-86.

Zou, Y., Liu, H., \& Wang, H. (2018). Evolution of contraception mix in China (2010-2016). Renkou Yanjiu (Population Research), 42(3), 3-16. (in Chinese).

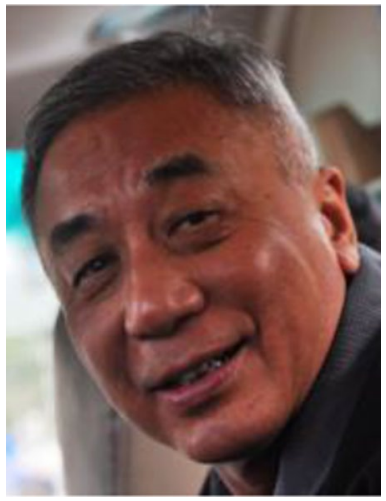

Baochang Gu Senior Research Associate, Center for Population and Development Policy Studies, Fudan University, Shanghai, CHINA. He received his B.A. in philosophy in Peking University in 1968, M.L. in international problems in Peking University in 1981, M.A. in 1984 and Ph.D. in 1986 in sociology and demography at the University of Texas at Austin, USA. 